\title{
REM sleep deprivation and conditioned fear in rats
}

\author{
ROBERT A. HICKS, GREGORY J. HICKS, and JOE R. REYES \\ San Jose State University, San Jose, California
}

\begin{abstract}
As a test of the hypothesis that REM sleep deprivation reduces fear, the freezing behavior of 60 rats was measured under the conditions of the Bolles-Collier (1976) paradigm. These animals were first exposed to one of three treatments for 4 days: a dry-environment control, a wetenvironment control, or a 4-day REM deprivation period. Next, the animals were fear conditioned in a square-box and then tested for freezing in either the square-box or a long-box. Finally, after a 4-day recovery period, the animals were retested. The REM-deprived group exhibited substantially less fear than did the control groups during these tests.
\end{abstract}

Several studies (Hicks et al., 1981; Hicks \& Moore, 1979; Hicks, Pettey, Okuda, \& Thomsen, 1979; Moore, Hayes, \& Hicks, 1979; Ogilvie \& Broughton, 1976) have provided data that suggest that REM sleep deprivation (RD) reduces fear in rats. Without exception, these data were derived from observations made during open-field tests, and this is a plausible hypothesis to the degree that one can assume that the open-field tests in these studies possess fear-evoking properties. The purpose of the present study was to provide a less ambiguous test of the hypothesis that $\mathrm{RD}$ reduces fear in rats, by manipulating the fear-evoking properties of the test situation. To this end, we made use of a modified form of a paradigm that Bolles and Collier (1976) developed for this purpose. They noted that rats conditioned to shock in a square-box and then given a 5-min postconditioning test in that box ( $\mathrm{S}-\mathrm{S}$ condition) displayed substantially higher levels of freezing (Bolles \& Collier's measure of fear) than did a group of rats that were first conditioned in the square-box and then tested in a long-box (S-L condition). Bolles and Collier concluded that fear seemed to be controlled primarily by the external shock-related cues of the square-box. Therefore, we felt that this paradigm provided a relatively straightforward means of testing the hypothesis that RD diminishes fear.

\section{METHOD}

\section{Subjects}

The subjects were 60 male Sprague-Dawley rats that were 68 days old at the time of testing. This age was selected so that we could contrast our data with those reported by others (Hicks \& Moore, 1979; Moore et al., 1979). The rats' weights ranged from 270 to $341 \mathrm{~g}$. Throughout the experiment, the animals were maintained on a 12:12 light-dark cycle, with lights on at 0600 , in a room that was held nearly constant at $22^{\circ} \mathrm{C}$. Food and water were continuously available throughout the experiment.

The rats were randomly assigned to one of three treatment groups: a 4-day REM-sleep-deprived group (Group SP, for small-platform), a

This research was supported by NIH-MBRS Grant RR 08192-07. Send reprint requests to Robert A. Hicks, Department of Psychology, San Jose State University, San Jose, CA 95192. large-platform control group (Group LP), or a dry-bucket-confinement control group (Group DC). The 20 animals within each of these groups were then randomly assigned to Bolles and Collier's (1976) S-S or S-L shock-conditioning-test conditions, so that six treatment $\times$ test condition groups of 10 animals each were formed.

\section{REM Deprivation}

RD was achieved by using a version of the water tank procedure (Jouvet, Vimont, Delorme, \& Jouvet, 1964) that had been modified for use with rats. The water tank procedure has been validated against appropriate electrophysiological measures of sleep (e.g., Mendelson, Gutherie, Frederick, \& Wyatt, 1974). Our RD apparatus and procedures have been described in detail elsewhere (Hicks \& Moore, 1979). All animals were confined to the RD apparatus for a 4-day period. The SP group spent this time on a small platform (diameter $=6.5 \mathrm{~cm}$ ) and thus were REM deprived. The LP group spent the RD treatment time on a large platform (diameter $=16.5 \mathrm{~cm}$ ), and thus acted as a non-REM-deprived control group for exposure to the water tank environment. The DC group spent the RD treatment period in a dry RD apparatus with the large platform in place, and therefore acted as a control for exposure to the novelty of this environment. (Note that the pretreatment-posttreatment weight differences were used as a rough check on the relative stressfulness of the SP and control treatments. The difference in weight change between these groups was not significant.)

\section{Fear Conditioning and Testing}

In many respects, the apparatus and the procedures used for fear (shock) conditioning and testing were identical with those employed by Bolles and Collier (1976). The essential differences between our apparatus and procedure and those of Bolles and Collier were as follows. Our boxes were constructed with higher sides $(46 \mathrm{~cm}$ vs. Bolles \& Collier's $35 \mathrm{~cm}$ ) to prevent escape. In the interest of economy, all our animals were fear conditioned in the square-box; that is, we did not use Bolles and Coilier's L-S and L-L conditions because their data suggested to us that this was not necessary. Finally, we did not vary the loudness of the masking tone as Bolles and Collier had done in their study.

The square-box was $29 \times 35 \times 46 \mathrm{~cm}$. The walls of this box were painted black and the floor was constructed of $1-\mathrm{cm}$ stainless steel bars spaced $2 \mathrm{~cm}$ center to center. The long-box was $76 \times 20 \times 46 \mathrm{~cm}$. The walls of this box were painted gray. Thus, we felt that the two boxes were discriminably different in their appearance. Both boxes were illuminated with a $15-\mathrm{W}$ bulb and extraneous sounds were masked during conditioning and testing with a 76-dB tone provided by a white-noise generator. During the 6-min conditioning period, each animal was placed in the square-box and permitted a 1-min habituation period. Then a 0.5 -sec shock (intensity $=1.0 \mathrm{~mA}$ ) was presented via a Grason-Stadler shock generator. In all, a total of five shocks were presented at 1-min intervals. One minute after the fifth shock, the animal was picked up and either returned to the square-box (S-S) or placed in the long-box 
(S-L). The first postconditioning test was started $1 \mathrm{~min}$ after the animal was placed in the appropriate test box and continued for a 20 -min period. During this test period, the animal's behavior was recorded via a lowlight video system for subsequent blind scoring of the number of freezes (our measure of level of fear, consistent with Bolles \& Collier, 1976).

\section{Procedure}

The animals were 60 days old when they arrived from the supplier. Prior to the 4-day treatment period, each animal was handled for a 10-min period each day for 4 days. Each animal was weighed just before it was assigned to its treatment. After the 4-day treatment period, each anima was towel dried, given a 10 -min rest period, run through the fear conditioning and testing procedures, and then weighed. All conditioning and testing procedures were carried out in the morning between 0900 and 1200. After this first test, the animals were housed in individual cages for a 4-day recovery period and then were retested in the box that had been used for their first test. Finally, 2 persons who were blind as to the animals' treatment viewed the videotapes of the animals' behavior and determined the number of freezes exhibited by each animal during each test. Like Hicks and Moore (1979) and Moore et al. (1979), we defined a freeze as the animal's remaining motionless for a 5-sec period.

\section{RESULTS AND DISCUSSION}

The mean number of freezes for each group for each test for the S-S and S-L conditions are listed in Table 1. The data summarized in Table 1 were tested by computing a three-factor analysis of variance with repeated measures in one factor (tests). The main effects for treatments $[F(2,54)=19.41, p<.001]$ and tests $[F(1,54)=$ $116.90, p<.001]$ were significant; however, the main effect for box conditions $[F(1,54)=.58]$ was not. In addition to these results, only the test $\times$ treatments interaction $[F(2,54)=19.76, p<.001]$ and the three-way interaction $[F(2,54)=4.30, p<.05]$ were significant.

The reasons for the significant main effects of treatments and tests are apparent from the pattern of means shown in Table 1. With regard to the former, the REM-deprived animals (Group SP) exhibited much less fear overall than did the controls. This pattern was especially pronounced during the immediate postconditioning test. The significant effect for tests was due to the fact that level of fear had considerably diminished for all groups over the 4-day recovery period. Since the animals were not shocked prior to the 4-day recovery test, this change probably reflects the decay of the conditioned fear response. It should be

Table 1

Freezing Score Means and Standard Deviations for Each Treatment by Box Condition

\begin{tabular}{|c|c|c|c|c|c|c|c|c|}
\hline \multirow[b]{3}{*}{ Group } & \multicolumn{4}{|c|}{ Immediate Test Condition } & \multicolumn{4}{|c|}{ 4-day Test Condition } \\
\hline & \multicolumn{2}{|c|}{ S-S } & \multicolumn{2}{|c|}{ S-L } & \multicolumn{2}{|c|}{ S-S } & \multicolumn{2}{|c|}{ S-L } \\
\hline & $M$ & $S D$ & $M$ & $S D$ & $M$ & $S D$ & $M$ & $S D$ \\
\hline SP & 11.2 & 10.0 & 22.0 & 22.0 & 7.5 & 12.0 & 2.8 & 4.1 \\
\hline LP & 86.0 & 45.4 & 93.9 & 71.1 & 10.0 & 8.5 & 8.0 & 14.8 \\
\hline DC & 141.8 & 64.8 & 89.0 & 43.4 & 19.8 & 29.8 & 25.2 & 38.8 \\
\hline
\end{tabular}

Note-S-S = conditioning and testing in a square-box; S-L = conditioning in a square-box and testing in long-box. Group SP (smallplatform) was deprived of REM sleep; Group LP was the large-platform control group; Group DC was the dry-bucket control group. noted, however, that Group SP also showed a decline in habit strength during this period and continued to display less fear than did either of the control groups.

As can be seen in Table 1, the significant interactions were the result of a complex pattern of reversals in the rank order of the S-S and S-L means that occurred between tests for all treatment groups. At present the best that can be said is that the reasons for these significant interactions are not clear. However, when these data are considered together with the nonsignificant main effect computed for the box conditions, it is obvious that the $\mathrm{S}-\mathrm{S}$ and $\mathrm{S}-\mathrm{L}$ conditions failed to produce the differential levels of fear that we had anticipated. We do not believe that these data should be taken as questioning the validity of the Bolles-Collier (1976) paradigm-none of our treated animals were exactly comparable to theirs, and, as we noted, we modified the square- and long-box conditions. Our modifications may have made these conditions less discriminable than those used by Bolles and Collier. Furthermore, these data do not suggest a failure of Bolles and Collier's shock-conditioning procedure as a method of inducing fear. On the contrary, this procedure was very effective in producing high levels of fear (as measured by freezing behavior). For example, when Hicks and Moore (1979) and Moore et al. (1979) measured freezing during a 20 -min open-field test as we did here (but without prior shock conditioning), they reported freezing means for the relevant treatment groups that were substantially lower than those we computed for our animals with either immediate or 4-day posttreatment tests. Thus, we conclude that the level of conditioned fear is lower in REM-deprived rats.

\section{REFERENCES}

Bolles, R. C., \& Collier, A. C. (1976). The effect of predictive cues on freezing in rats. Animal Learning \& Behavior, 4, 6-8.

Hicks, R. A., Gomez, S., Gonzales, L., Kuroda, M., Orme, N., \& REYES, J. (1981). REM sleep deprivation reduces emotionality in famale rats. Bulletin of the Psychonomic Society, 17, 244-245.

Hicks, R. A., \& MOORE, J. D. (1979). REM sleep deprivation diminishes fear in rats. Physiology \& Behavior, 22, 689-692.

Hicks, R. A., Pettey, B., OKuda, A., \& Thomsen, D. (1979). The effects of REM sleep deprivation and age on locomotor activity in rats. Psychological Record, 29, 355-360.

Jouvet, D., Vimont, P., Delorme, F., \& Jouvet, M. (1964). Étude de la privation selective de la phase paradoxale de sommeil chez le chat. Comptes Rendus de la Société de Biologie, 158, 756-759.

Mendelson, W. B., Gutherie, R. D., Frederick, G., \& Wyatt, R. J. (1974). The flower-pot technique of rapid eye movement (REM) sleep deprivation. Pharmacology, Biochemistry \& Behavior, 2, 553-556.

Moore, J. D., Hayes, C., \& HiCKs, R. A. (1979). REM sleep deprivation increases preference for novelty in rats. Physiology \& Behavior, 23, 975-976.

OGILvie, R. D., \& Broughton, R. J. (1976). Sleep deprivation and measures of emotionality in rats. Psychophysiology, 13, 249-260.

(Manuscript received for publication June 1, 1987.) 